\title{
THE MODULATORY EFFECT OF PHYSICAL ACTIVITY ON APE1-MEDIATED TELOMERE LENGTH AND STABLLITY; A NARRATIVE REVIEW
}

\author{
Gabriela Betlej,, ${ }^{\mathrm{A} D}$ Aleksandra Kwiatkowska, ${ }^{\mathrm{D}}$ Ewelina Bator ${ }^{\mathrm{A}, \mathrm{D}}$ \\ University of Rzeszow, College of Medical Sciences, Institute of Physical Culture Studies, Poland

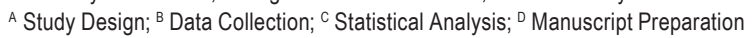 \\ Address for corpespondence: \\ Gabriela Betlej \\ University of Rzeszow, College of Medical Sciences, Institute of Physical Culture Studies \\ Towarnickiego 3, 35-959 Rzeszów, Poland \\ E-mail: gbetlej@ur.edu.pl
}

\begin{abstract}
Ahstract Physical activity is associated with enhanced generation of reactive oxygen species (ROS) that, in turn, can play a dual role in the human body. Upon physiological conditions, ROS act as secondary messengers in different cell signaling pathways. In contrast, ROS overexpression can lead to oxidative stress and oxidative stress-associated harmful consequences. This exercise-induced interplay among oxidants and antioxidants can modulate numerous physiological and molecular mechanisms, for example telomere length maintenance and stability. The latter is, in turn, under strict control of oxidative stress-activated base excision repair (BER) pathway, one of the DNA repair mechanisms; and growing evidence directs attention to apurinic/ apyrimidinic endonuclease 1 (APE1), a multifunctional BER protein. Therefore, this review intends to address several issues concerning modulatory effect of exercise on APE1-mediated telomere length maintenance and redox activities.
\end{abstract}

Key worlls physical activity, telomeres, BER DNA repair, APE1, oxidative stress

\section{Introduction}

It is widely agreed upon that physical activity has a significant impact on human health. However, depending on a wide range of agents and mechanisms, physical effort may have beneficial or harmful effects (Radak, Chung, Goto, 2005). Among exercise-associated factors that mediate many physiological processes is oxidative stress. Although its role per se is relatively well-established and documented in numerous studies, several oxidative stressdriven mechanisms are still poorly recognized or remain unclear. One of such a phenomenon is exercise-dependent telomere length maintenance and stability. Although telomeres shortening is a natural phenomenon related with replication, there are some evidence suggesting that there is a link between physical activity and telomere length and stability (Ludlow, Ludlow, Roth, 2013). This relationship may be, in turn, mediated by oxidative stress-dependent activation of base excision repair (BER) mechanism at telomeric ends. Although, molecular-level details of this putative relationship are unclear, growing evidence suggest that protein-protein interactions between telomeric 
shelterin and BER proteins might be the key mechanism (Miller, Balakrishnan, Buncher, Opresko, Bambara, 2012). Among BER proteins, apurinic/apyrimidinic endonuclease 1 (APE1), a multifunctional protein, seems to play a crucial role in linking DNA repair, including telomeric sequences, gene expression and redox activities (Madlener, Ströbel, Vose, Saydam, Price, Demple, Saydam, 2013). Therefore, a modulatory effect of physical activity on telomere length and stability will be discussed here with emphasis on APE1.

\section{Telomeres - structure and function}

Telomeres (TL) are heterochromatic domains localized at the end of linear eukaryotic chromosomes. Telomeric DNA is constructed of tandem repeating nucleotide sequences (5'-TTAGGG-3'), connected to a series of specialized proteins that determine their stability and shape (de Lange, 2005; Blackburn, 2005). Telomeres shorten every round of replication due to the inability of DNA polymerases to fully replicate the end of the leading (G-rich) strand.

The shelterin is a multiprotein complex consists of 6 protein subunits: TRF1, TRF2 (telomere repeat factor $-1,-2$ ), POT1 (protection of telomere protein -1), TIN2 (TRF1-interacting protein 2), Rap1 (repressor/activator protein 1), and TPP1 (tripeptidyl pepti-90 dase 1). They protect telomeres by maintaining telomere structure, repress the DNA repair machinery at telomeres, and regulate telomere length (Palm, de Lange, 2008).

The shelterin complex interacts directly with the telomere and can modulate telomere length through allowing access to positive and negative regulators of telomere length in both telomerase-dependent and -independent mechanisms. TRF1 and TRF2 bind as homodimers to the double stranded telomeric DNA repeats. POT1 binds with high specificity to the single-stranded 5'-TTAGGG-3' repeat DNA (Baumann, Cech, 2001). TPP1, TIN2 and Rap1 associate with telomeres through interactions with protein-protein connections. TRF1 and TIN2 regulate telomere length, whilst TRF2 prevents end to end fusion and activation of DNA damage response. It has been reported that, additional proteins capable of interacting with telomeric proteins which are involved in DNA damage response and double-strand break repair also have implications for telomere length regulation and chromosome end protection (Denchi, de Lange, 2007).

Shelterin protein binds to telomeric DNA, forming the unique telomeric chromatin structure called t-loop. By creating t-loops, telomeres generate closed configuration that protects the chromosome ends from being recognized by the DNA damage repair machinery (de Lange, 2009). Another important functions of shelterin is blocking the ataxia telangiectasia mutated (ATM)/ataxia telangiectasia and rad3 related (ATR) damage response pathways and suppressing double-strand break repair activities at chromosome ends, thereby preventing linear chromosome ends from erroneously being recognized as damaged DNA. In addition, shelterin proteins control telomere length via regulating telomerase recruitment and/or modulating telomerase activity at chromosome ends (de Lange, 2009; Palm, de Lange 2008).

Telomere length can be controlled indirectly by shelterin protein complex and directly by the telomerase enzyme.

The end-replication problem is overcome by the enzyme telomerase that maintains telomere length homeostasis by adding 5'-TTAGGG-3' repeats to telomeres following DNA replication. Telomerase is a cellular reverse transcriptase that consists of two components, a reverse transcriptase subunit known as telomerase reverse transcriptase (hTERT) and a telomerase RNA component (hTERC) (Blasco, 2003). It seems that the hTERT 
subunit is a factor limiting the functional telomerase activity, it can be used as an indicator of the telomerase function (Chilton et al., 2014).

What is more, single-stranded, guanine-rich polynucleotide sequences have the ability to form quadratic structures called G-quadruplexes (G4), stabilized by Hoogten hydrogen bonds and additionally by a metal cation (usually potassium or sodium). Telomeric DNA has also tendency to fold in to G4 structure. What is more, at least four repeats of the human telomeric motif TTAGGG fold into a variety of (G4) conformations in vitro (Bugaut, Alberti, 2015). This conformation prevents access of exonucleases to the terminal sections of telomeres and protects the single DNA strand from degradation, they become non-accessible for the replication machinery (Bochman, Paeschke, Zakian, 2012). Studies have reported that DNA damage, in particular oxidative damage, significantly affects $\mathrm{G} 4$ structures. Under oxidative stress conditions, oxidized products of DNA bases and abasic sites may be generated. Absence the purine decreases thermal stability of the structure G4 (Babinský et al., 2014). Furthermore, formation of telomeric G4 structure has been shown to inhibit the telomerase activity (Zahler, Williamson, Cech, Prescott, 1991).

\section{Why telomeres shorten?}

Telomeres shorten during DNA replication due to the „end-replication problem”, in which the DNA polymerase enzyme cannot fully copy the end of the DNA strand. This phenomenon was firstly described by A.M. Olovnikov and J.D. Watson independently and later confirmed by Harley (Olovnikov, 1971; Watson, 1972; Harley, Futcher, Greider, 1990).

What is more, telomere shortening, which is associated with each cell division, disrupts protective shelterin complex and leads to a DNA damage response (DDR) and activation of the senescence programme (Griffith et al., 1999).

Another reason why telomere shorten is damage accumulation that disturbs proper cell functioning. There are a lot of factors leading to DNA damage which all falls in one of two group: environmental factors (also called as external) or naturally occurring (called as internal factor). The most common for the first group is UV radiation, ionizing radiation and numerous genotoxic chemicals. The second group include errors during replication processes and reactive species i.e. oxygen, nitrogen, carbonyl, lipid peroxidation products and many more, which are able to hydrolysis cleaves chemical bonds in DNA (Jackson, Bartek, 2009). One of the most common DNA damage is lesion caused by increasing levels of ROS. Telomeres are particularly sensitive to base oxidation by ROS because of the large number of guanosine $(G)$ nucleotides in their repeating sequence which will cause accelerate telomere attrition (Oikawa, Kawanishi, 1999). An imbalance between reactive oxygen species and antioxidants induce oxidative stress. To counteract excessive oxidative stress, and maintain a proper prooxidant/antioxidant balance, humans possess an extensive and efficient antioxidant defense system, containing endogenous antioxidant enzymes and non-enzymatic antioxidants (Powers, Jackson, 2008).

\section{A role of ROS-driven DNA base excision repair (BER) in telomeric ends maintenance}

Although under physiological conditions, ROS are important factors involved in cell signaling and immune system responses (Ścibior-Bentkowska, Czeczot, 2009), their increased level may lead to oxidative stress and oxidative stress-associated pathophysiological mechanisms, such as cardiovascular diseases (Dhalla et al., 2000), 
metabolic syndrome (Bonomini, Rodella, Rezzani, 2015), neurodegenerative alternations (Sorce, Krause, 2009), as well as cancer (Reuter, Gupta, Chaturvedi, Aggarwal, 2010).

On the molecular level, increased ROS level can lead to significant cellular dysfunctions and oxidative damages to macromolecules, including proteins, lipids, and DNA (Zuo, Hallman, Yousif, Chien, 2012). The latter is thought to be the most deleterious, because - if unrepaired - might result in an increased rate of mutations and genome instability. One of the most common oxidative DNA lesions are several oxidized guanine products, including the well-documented biomarker of oxidative stress, that is 8-oxo-7,8-dihydroguanine (8-oxoG) (Wang et al., 2010; David, O'Shea, Kundu, 2007). 8-oxoG occurrence in DNA activates 8-oxoguanine DNA glycosylase (OGG1) and OGG1-mediated DNA base excision repair (BER) pathway (Wang et al., 2010; David et al., 2007).

Although there are many DNA repair mechanisms that are activated in response to a wide range of DNA lesions, BER pathway is the most common one at telomeric sequences, because triple guanine repeats, that are one of the features of telomeres, make them particularly susceptible to ROS-driven oxidation and, consequently, 8-oxoG generation (Wang et al., 2010). Moreover, some mechanisms - in particular, both standard and alternative nonhomologous end joining (NHEJ) (Webb et al., 2013) as well as canonical recombination repair (HR) that cope mainly with double strand DNA breaks (DSBs) - are generally inhibited at telomeres (Webb et al., 2013; Marcand, 2014; Claussin, Chang, 2015) to prevent telomeric ends from being recognized and repaired as DSBs (Webb, Wu, Zakian, 2013).

As mentioned above, OGG1-initiated BER pathway plays a crucial role in repairing and maintaining telomeric sequences. OGG1 recognizes and removes damaged bases and this action results in generation of apurinic/ apyrimidinic (AP) site. Next, apurinic/apyrimidinic endonuclease 1 (APE1) cleaves phosphodiester bonds in DNA in the 5 ' direction from the AP site. APE1 action leaves a nucleotide gap, which is then repaired by short-patch (in the case of a single nucleotide gap) or long-patch repair (if break consists of more than one nucleotide). Missing nucleotide/s are synthesized by DNA polymerase $\beta$ (Pol $\beta)$ and a single strand DNA break is sealed due to the orchestrated action of the DNA repair enzyme DNA ligase III and XRCC1 or by the replicative DNA ligase I (Jia, Her, Chai, 2015; Krokan, Bjørås, 2013).

To date, a majority of research has focused on the role of OGG1 in BER-based response to oxidative stress at telomeric sequences, while several of them concern on relations between OGG1 level and/or activity and physical effort (Radak et al., 2011). However, even less is known about the potential modulatory effect of APE1 activity on response to physical activity-induced oxidative stress. Such a role seems to be consequential to the multifunctional characteristics of APE 1 that combines DNA repair (including telomeric ends), gene expression regulation and redox activities (Xanthoudakis, Smeyne, Wallace, Curran, 1996; Poletto et al., 2013; Burra et al., 2019).

The human APE1 protein is encoded by the APE1 gene located on chromosome 14. The gene consists of 5 exons and 4 introns, and the encoded protein has 318 amino acids (Robson et al., 1992). Homologues of human APE1 protein have been identified in many organisms. It has been shown that the $\mathrm{C}$-terminus is highly evolutionarily conserved. In contrast, the N-domain, although is characteristic for many species, is absent in some of them (for example in Escherichia coli) (Li, Wilson, 2014) (Figure 1).

These two abovementioned domains of APE1 exhibit two different activities. The N-terminal one, which contains the nuclear localization signal (NLS) sequence, acts as a redox co-activator that promotes DNA-binding activity of several transcription factors, e.g. nuclear factor-kB (NF-kB), p53, hypoxia inducible factor-1a (HIF$1 a)$, early growth response protein-1 (Egr-1). Therefore, APE1 is also known as redox effector factor 1 (Ref-1) 


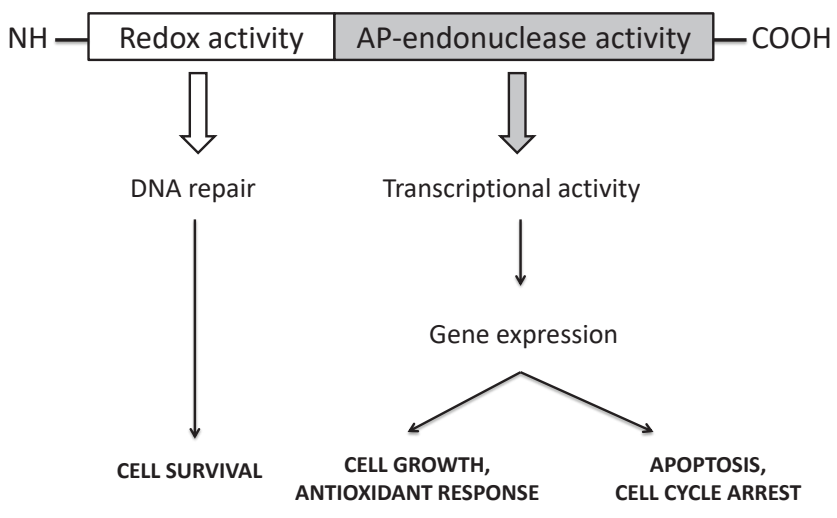

Figure 1. Schematic structure of APE1 protein and its role in different molecular pathways and cellular processes

(Xanthoudakis et al., 1996; Tell, Quadrifoglio, Tiribelli, Kelley, 2009; Poletto et al., 2013; Burra et al., 2019). In turn, C-terminus (61-318 aa) is responsible for AP-endoribonuclease activity and plays a key role in DNA damage repair pathways, including BER (Wang et al., 2010; David et al., 2007). Both functions are independent from each other (Xanthoudakis, Miao, Curran, 1994).

\section{Physical activity and telomeres hiology}

It is well known that regular physical activity is associated with healthy aging and reduced risk for a number of chronic conditions (Bauman, Cech, 2001). Correlation between physical activity, sedentary behavior, telomere length and DNA repair has been extensively studied, but the relationship between those factors remains unclear.

Many scientific reports demonstrated that during physical activity ROS level increase. The production of those molecules during exercise is associated primarily with the functioning of mitochondria, NADPH oxidase and xanthine oxidase and have dual functions. On the one hand, with extremely strong activity, there is an excessive ROS outburst, which, by oxidizing biomolecules, destroy cellular components, causing a reduction in the physical capacity of the body. However, when the training is properly balanced, suited to the athlete's trained and endurance conditions, ROS become a positive modulator leading to rearrangement of skeletal muscles, stimulate the immune system or activate adaptive antioxidant systems (Radak et al., 2005).

Regular physical activity is associated with longer telomeres and could attenuate telomere attrition. The relationship between physical activity and telomere biology is becoming the subject of research for an increasing number of researchers but still remain elusive. As cross-sectional studies show, the relationship between physical activity and the length of telomeres, mainly in immune cells, can have different effects: a positive relationship with telomere length, no correlation or an inverted "U" correlation were observed. In inverse "U" correlation, sedentary individuals and extremely active athletes have shorter telomeres than moderately active subjects (Ludlow et al., 2013). But it is true that most of available research indicates that higher physical activity exhibits a positive relationship with longer leukocyte or skeletal muscle telomere length in comparison to a sedentary lifestyle.

Recent work indicates that endurance training can provide a protective effect on the telomeres length and alleviate the biological aging process (Mundstock et al., 2015). As T.J. LaRocca and colleagues' studies show, 
older (55-72 years), athletic men have comparable telomere lengths to their young physically active colleagues (La Rocca, Seals, Pierce, 2010). In addition, young athletes have longer telomeres than their inactive colleagues (Muniesa et al., 2017). Recent studies conducted at master athletes showed that they have longer telomere, better oxidative profile, and lower body fat than untrained individuals. What is more, body fat was inversely correlated with both telomere length and markers of oxidative balance (Aquiar et al., 2019). J. Denham and coworkers showed that endurance athletes had longer telomeres than compared to non-trained group (Denham et al., 2013). Also, long-term endurance or interval training intervention increase telomeres length and telomerase activity in previously sedentary individuals (Werner et al., 2019). Other study performed both on the mouse model and on human leukocytes demonstrated that physical activity regulates telomere-stabilizing proteins and thereby protects from stress-induced vascular apoptosis. Peripheral blood leukocytes isolated from endurance athletes showed increased telomerase activity, expression of telomere-stabilizing proteins, and downregulation of cellcycle inhibitors compared with untrained individuals. Long-term endurance training was associated with reduced leukocyte telomere shortening compared with untrained controls (Werner et al., 2009). It has also been reported that the higher the level of physical activity and the amount of physical activity per week could translate in longer telomeres (Latifovitc, Peacock, Massey, King, 2016; Edwards, Loprinzi, 2017; Du et al., 2012). In opposite to study performed by H.G. Simoes et al. (2017), where master sprinters had longer TL, lower body fat and BMI, and a better lipid profile than age-matched controls, study performed by C. Mason et al. (2013) showed that leukocyte telomere length is positively associated with baseline VO2 max (the maximum volume of oxygen that can be utilize during exercise which is a universal indicator of physical fitness) and inversely associated with age, while unassociated with BMI and percent body fat. Interestingly, Y. Shin et al. (2008) determine the changes of antioxidant levels after exercise training, and these enzyme activities were increased following long-term exercise training; but the lengths of telomere were not changed by both mid-intensity and high intensity of exercise stress. A. Borghini's group also showed that chronic endurance training can provide a protective effect related to shortening telomeres, thereby mitigating the effects of biological age. However, acute exposure to a long-distance race may contribute to the shortening of telomeres, which may be related to oxidative DNA damage (Borghini et al., 2015). It seems that regular and moderate intensity of physical activity has beneficial effect on telomere length.

\section{APE1 is also involved in ensuring genome stability and integrity through telomeres protection}

As it was mentioned earlier, during oxidative stress, the accumulation of 8-0xoG in telomeres is increased significant within the telomeric DNA sequences, and telomeres are less efficiently repaired than the rest of the genome. When 8-0xoG is not properly repaired, it induces a GC-TA mutation, which can lead to genomic instability. Previous studies have demonstrated that oxidative stress causes SSBs in telomeric DNA (Zglinicki, Pilger, Sitte, 2000). In addition, the presence of 8-0xoG inhibits telomerase activity and reduces binding of telomeric proteins, mainly TRF1 and TRF2, to the telomere sequence, which leads to the destabilization of the telomeric structure (Opresko, Fan, Danzy, Wilson, Bohr, 2005).

$\mathrm{G} 4$ is a specific structure that may trigger DNA damage and genome instability. This conformation prevents access of exonucleases to chromosomes ends, nevertheless, access to repair proteins is also hampered. However, it was demonstrated that APE1 is able to bind to quadruplex structure and promote lesions repair (Broxson, Hayner, Beckett, Bloom, Tornaletti, 2014). Further studies indicated that APE1 N-terminal sequence is required and essential for regulating APE1 enzymatic activity on G4- telomeric structure (Burra et al., 2019). Interestingly, 
BER is a key DNA repair pathway promoted in telomeres which is stimulated through proteins included in telomere shelterin complex, such as TRF1, TRF2 or POT1 (Miller et al., 2012). Moreover, there are protein-protein interactions between those proteins and APE1. It has been found that APE1 is able to bind to telomeres (Li et al., 2018) and an enrichment of AP endonuclease at telomeres is promoted by TRF1, TRF2 or POT1. It was also shown that proteins included in telomere shelterin complex enhance APE1 ability to cleavage on telomeric substrate (Miller et al., 2012). Furthermore, APE1 is require for proper binding of TRF2 to chromosomes ends.

S. Madlener and co-workers (2013) analyzed what happened with telomeres in APE1-depleted human cells lines. Their results showed that APE1 deficiency leads to segregation defects and mitotic failure. FISH analysis revealed a number of telomeres dysfunction such as: chromosome end fragmentation, telomere signal loss and chromosome end-to-end fusions. Further studies confirmed that depletion of APE1 disrupts the association of TRF2. Moreover, terminal telomere fragments in APE1-depleted cells shortened during just 3 days of siRNA treatment in the investigated cell lines.

Although it has been shown that physical activity may be involved in modulation of DNA repair mechanisms (Schmidt, Nickerson, Boatright, 2016; Yang, Yu-Lin, Chuang, Bohr, Mattson, 2014; Laye et al., 2012; Radak et al., 2011), much less is known about the modulatory effect of physical activity on APE1 activity. Moreover, these data are often in contrary with each other. On the one hand, Z. Radak and coworkers (2011) demonstrated that neither APE1 nor its acetylated isoform, Ac-APE1, showed significant changes with aging and/or physical activity in human skeletal muscles. Such a modulatory effect exhibited, in turn, acetylated isoform of OGG1 and thereby, it has been considered as a rate-limiting factor in the BER pathway. Moreover, Z. Radak et al. concluded that, in general, repair of 8-oxoG indeed depends on physical state of muscles. Consequently, oxidative stress induced by physical effort mediates the adaptive response for effective repair of DNA lesion, especially through BER mechanism (Radak et al., 2011).

In contrary to findings obtained by Z. Radak et al. (2011), there is a report showing significant increases in APE1 levels in cerebral cortex and hippocampus of mice in response to 10-day period of voluntary running wheel exercise compared to the sedentary control mice (Yang et al., 2014).

Nevertheless, none of these studies have focused on APE1-mediated control of telomere length and stability in response to exercise. Perhaps, correlation between physical activity and DNA repair mechanisms may be a key for genomic stability promotion by telomeres structure stabilization and higher effectiveness of DNA lesions repair.

\section{Conclusions}

Significant progress has been made in understanding how ROS effects on telomere length maintaining. Telomeres integrity is a key feature of linear chromosomes, responsible for genome stability, however, the tandem repeats found in telomeres affect the increased sensitivity to oxidative stress, which can lead to genomic instability. Growing evidence indicate connection between telomere length and lifestyle factors. It is well established that during physical exercise ROS production increases. Therefore, experimental data demonstrating the link between physical activity and telomeres length are still unclear. Physical activity may be beneficial for telomere maintenance and protect telomeric DNA from damage. Mechanisms of telomeric DNA repair and mechanisms regulating telomeres activity may constitute a new approach in therapies, regeneration and increase of endurance in active people.

It seems that the special involvement of APE-1 in telomeres biology, especially shelterin proteins, can favorably modulate telomere maintenance, improve well-being and inhibit aging processes. However, more studies 
are needed, especially those with type of exercise intervention, duration, intensity of exercise on telomere length and telomeric DNA repair. This is especially important in the context of aging and the occurrence of diseases where inflammation and oxidative stress may occur.

\section{Referenences}

Aguiar, S.S., Rosa, T.S., Sousa, C.V., Santos, P.A., Barbosa, L.P., Deus, L.A., Rosa, E.C., Andrade, R.V., Simoes, H.G. (2019). Influence of Body Fat on Oxidative Stress and Telomere Length of Master Athletes. Journal of Strength and Conditioning Research.

Babinský, M., Fiala, R., Kejnovská, I., Bednářová, K., Marek, R., Sagi, J., Sklenar, V., Vorlickova, M. (2014). Loss of loop adenines alters human telomere dAG3(TTAG3)3 quadruplex folding. Nucleic Acids Research, 42 (22), 14031-14041.

Baumann, P., Cech, T.R. (2001). Pot1, the putative telomere end-binding protein in fission yeast and humans. Science (New York, N.Y.), 292 (5519), 1171-1175.

Blackburn, E.H. (2005). Telomeres and telomerase. Their mechanisms of action and the effects of altering their functions. FEBS Letters, 579 (4), 859-862.

Blasco, M.A. (2003). Mammalian telomeres and telomerase. Why they matter for cancer and aging. European Journal of Cell Biology, $82(9), 441-446$.

Bochman, M.L., Paeschke, K., Zakian, V.A. (2012). DNA secondary structures. Stability and function of G-quadruplex structures. Nature Reviews. Genetics, 13 (11), 770-780.

Bonomini, F., Rodella, L.F., Rezzani, R. (2015). Metabolic syndrome, aging and involvement of oxidative stress. Aging and Disease, 6 (2), 109-120.

Borghini, A., Giardini, G., Tonacci, A., Mastorci, F., Mercuri, A., Mrakic-Sposta, S., Moretti, S., Andreassi, M.G., Pratali, L. (2015). Chronic and acute effects of endurance training on telomere length. Mutagenesis, 30 (5), 711-716.

Broxson, C., Hayner, J.N., Beckett, J., Bloom, L.B., Tornaletti, S. (2014). Human AP endonuclease inefficiently removes abasic sites within G4 structures compared to duplex DNA. Nucleic Acids Research, 42 (12), 7708-7719.

Bugaut, A., Alberti, P. (2015). Understanding the stability of DNA G-quadruplex units in long human telomeric strands. Biochimie, 113, 125-133.

Burra, S., Marasco, D., Malfatti, M.C., Antoniali, G., Virgilio, A., Esposito, V., Demple, B., Galeone, A., Tell, G. (2019). Human APendonuclease (Ape1) activity on telomeric $\mathrm{G} 4$ structures is modulated by acetylatable lysine residues in the $\mathrm{N}$-terminal sequence. DNA Repair, 73, 129-143.

Chilton, W.L., Marques, F.Z., West, J., Kannourakis, G., Berzins, S.P., O’Brien, B.J., Charchar, F.J. (2014). Acute exercise leads to regulation of telomere-associated genes and microRNA expression in immune cells. PloS One, 9 (4).

Claussin, C., Chang, M. (2015). The many facets of homologous recombination at telomeres. Microbial cell (Graz, Austria), 2 (9), 308-321.

David, S.S., O'Shea, V.L., Kundu, S. (2007). Base Excision Repair of Oxidative DNA Damage. Nature, 447 (7147), $941-950$.

De Lange, T. (2005). Shelterin. The protein complex that shapes and safeguards human telomeres. Genes \& Development, 19 (18), 2100-2110.

De Lange, T. (2009). How telomeres solve the end-protection problem. Science (New York, N.Y.), 326 (5955), 948-952.

Denchi, E.L., de Lange, T. (2007): Protection of telomeres through independent control of ATM and ATR by TRF2 and POT1. Nature, 448 (7157), 1068-1071.

Denham, J., Nelson, C.P., O’Brien, B.J., Nankervis, S.A., Denniff, M., Harvey, J.T., Marques, F.Z., Codd, V., Zukowska-Szczechowska, E., Samani, N.J., Tomaszewski, M., Charchar, F.J. (2013). Longer leukocyte telomeres are associated with ultra-endurance exercise independent of cardiovascular risk factors. PloS One, 8 (7).

Dhalla, N.S., Temsah, R.M., Netticadan, T. (2000). Role of oxidative stress in cardiovascular diseases. Journal of Hypertension, 18 (6), 655-673.

Du, M., Prescott, J., Kraft, P., Han, J., Giovannucci, E., Hankinson, S.E., de Vivo, I. (2012). Physical activity, sedentary behavior, and leukocyte telomere length in women. American Journal of Epidemiology, 175 (5), 414-422.

Edwards, M.K., Loprinzi, P.D. (2017). Sedentary behavior, physical activity and cardiorespiratory fitness on leukocyte telomere length. Health Promotion Perspectives, 7 (1), 22-27. 
Griffith, J.D., Comeau, L., Rosenfield, S., Stansel, R.M., Bianchi, A., Moss, H., de Lange, T. (1999). Mammalian telomeres end in a large duplex loop. Cell, 97 (4), 503-514.

Harley, C.B., Futcher, A.B., Greider, C.W. (1990). Telomeres shorten during ageing of human fibroblasts. Nature, 345 (6274), 458-460.

Jackson, S.P., Bartek, J. (2009). The DNA-damage response in human biology and disease. Nature, 461 (7267), 1071-1078.

Jia, P., Her, C., Chai, W. (2015). DNA Excision Repair at Telomeres. DNA Repair, 36, 137-145.

Krokan, H.E., Bjørås, M. (2013). Base excision repair. Cold Spring Harbor Perspectives in Biology, 5 (4).

LaRocca, T J., Seals, D.R., Pierce, G.L. (2010). Leukocyte telomere length is preserved with aging in endurance exercise-trained adults and related to maximal aerobic capacity. Mechanisms of Ageing and Development, 131 (2), 165-167.

Latifovic, L., Peacock, S.D., Massey, T.E., King, W.D. (2016). The Influence of Alcohol Consumption, Cigarette Smoking, and Physical Activity on Leukocyte Telomere Length. Cancer Epidemiology, Biomarkers \& Prevention, 25 (2), 374-380.

Laye, M.J., Solomon, T.P.J., Karstoft, K., Pedersen, K.K., Nielsen, S.D., Pedersen, B.K. (2012). Increased shelterin mRNA expression in peripheral blood mononuclear cells and skeletal muscle following an ultra-long-distance running event. Journal of Applied Physiology (Bethesda, Md., 1985), 112 (5), 773-781.

Li, M., Wilson, D.M. (2014). Human apurinic/apyrimidinic endonuclease 1. Antioxidants \& Redox Signaling, 20 (4), 678-707.

Li, M., Yang, X., Lu, X., Dai, N., Zhang, S., Cheng, Y., Zhang, L., Yang, Y., Liu, Y., Wang, D., Wilson, D.M. (2018). APE1 deficiency promotes cellular senescence and premature aging features. Nucleic Acids Research, 46 (11), 5664-5677.

Ludlow, A.T., Ludlow, L.W., Roth, S.M. (2013). Do telomeres adapt to physiological stress? Exploring the effect of exercise on telomere length and telomere-related proteins. BioMed Research International.

Madlener, S., Ströbel, T., Vose, S., Saydam, O., Price, B.D., Demple, B., Saydam, N. (2013). Essential role for mammalian apurinic/ apyrimidinic (AP) endonuclease Ape1/Ref-1 in telomere maintenance. Proceedings of the National Academy of Sciences of the United States of America, 110 (44), 17844-17849.

Marcand, S. (2014). How do telomeres and NHEJ coexist? Molecular \& Cellular Oncology, 1 (3).

Mason, C., Risques, R.A., Xiao, L., Duggan, C.R., Imayama, I., Campbell, K.L., Kong, A., Foster-Schubert, K.E., Wang, C.Y., Alfano, C.M., Blackburn, G.L., Rabinovitch, P.S., McTiernan, A. (2013). Independent and combined effects of dietary weight loss and exercise on leukocyte telomere length in postmenopausal women. Obesity (Silver Spring, Md.), 21 (12).

Miller, A.S., Balakrishnan, L., Buncher, N.A., Opresko, P.L., Bambara, R.A. (2012). Telomere proteins POT1, TRF1 and TRF2 augment long-patch base excision repair in vitro. Cell cycle (Georgetown, Tex.), 11 (5), 998-1007.

Mundstock, E., Zatti, H., Louzada, F.M., Oliveira, S.G., Guma, F.T.C.R., Paris, M.M., Rueda, A. B., Machado, D.G., Stein, R.T., Jones, M.H., Sarria, E.E., Barbe-Tuana, F.M., Mattiello, R. (2015). Effects of physical activity in telomere length. Systematic review and meta-analysis. Ageing Research Reviews, 22, 72-80.

Muniesa, C.A., Verde, Z., Diaz-Ureña, G., Santiago, C., Gutiérrez, F., Díaz, E., Gomez-Gallego, F., Pareja-Galeano, H., SoaresMiranda, L., Lucia A. (2017). Telomere Length in Elite Athletes. International Journal of Sports Physiology and Performance, $12(7), 994-996$.

Oikawa, S., Kawanishi, S. (1999). Site-specific DNA damage at GGG sequence by oxidative stress may accelerate telomere shortening. FEBS Letters, 453 (3), 365-368.

Olovnikov, A.M. (1971). Printsip marginotomii v matrichnom sinteze polinukleotidov. Doklady Akademii Nauk SSSR, 201 (6), $1496-1499$.

Opresko, P.L., Fan, J., Danzy, S., Wilson, D.M., Bohr, V.A. (2005). Oxidative damage in telomeric DNA disrupts recognition by TRF1 and TRF2. Nucleic Acids Research, 33 (4), 1230-1239.

Palm, W., de Lange, T. (2008). How shelterin protects mammalian telomeres. Annual Review of Genetics, 42, 301-334.

Poletto, M., Vascotto, C., Scognamiglio, P.L., Lirussi, L., Marasco, D., Tell, G. (2013). Role of the unstructured N-terminal domain of the hAPE1 (human apurinic/apyrimidinic endonuclease 1) in the modulation of its interaction with nucleic acids and NPM1 (nucleophosmin). The Biochemical Journal, 452 (3), 545-557.

Powers, S.K., Jackson, M.J. (2008). Exercise-induced oxidative stress. Cellular mechanisms and impact on muscle force production. Physiological Reviews, 88 (4), 1243-1276.

Radak, Z., Bori, Z., Koltai, E., Fatouros, I.G., Jamurtas, A.Z., Douroudos, I.I., Terzis, G., Nikolaidis, M.G., Chatzinikolaou, A., Sovatzidis, A., Kumagai, S., Naito, H., Boldogh, I. (2011). Age-dependent changes in 8-oxoguanine-DNA glycosylase activity are modulated by adaptive responses to physical exercise in human skeletal muscle. Free Radical Biology \& Medicine, 51 (2), $417-423$.

Radak, Z., Chung, H.Y., Goto, S. (2005). Exercise and hormesis. Oxidative stress-related adaptation for successful aging. Biogerontology, $6(1), 71-75$. 
Reuter, S., Gupta, S.C., Chaturvedi, M.M., Aggarwal, B.B. (2010). Oxidative stress, inflammation, and cancer. How are they linked? Free Radical Biology \& Medicine, 49 (11), 1603-1616.

Robson, C.N., Hochhauser, D., Craig, R., Rack, K., Buckle, V.J., Hickson, I.D. (1992). Structure of the human DNA repair gene HAP1 and its localisation to chromosome 14q 11.2-12. Nucleic Acids Research, 20 (17), 4417-4421.

Ścibior-Bentkowska, D., Czeczot, H. (2009). Komórki nowotworowe a stres oksydacyjny. Postępy Higieny i Medycyny Doświadczalnej, $63,58-72$.

Shin, Y.A., Lee, J.H., Song, W., Jun, T.W. (2008). Exercise training improves the antioxidant enzyme activity with no changes of telomere length. Mechanisms of Ageing and Development, 129 (5), 254-260.

Schmidt, R.H., Nickerson, J.M., Boatright, J.H. (2016). Exercise as Gene Therapy: BDNF and DNA Damage Repair. Asia Pac J Ophthalmoll, 5 (4), 309-311.

Simoes, H.G., Sousa, C.V., Dos Santos Rosa, T., da Silva Aguiar, S., Deus, L.A., Rosa, E.C.C.C., Amato, A.A., Andrade, R.V. (2017). Longer Telomere Length in Elite Master Sprinters. Relationship to Performance and Body Composition. International Journal of Sports Medicine, 38 (14), 1111-1116.

Sorce, S., Krause, K.H. (2009). NOX enzymes in the central nervous system. From signaling to disease. Antioxidants \& Redox Signaling, $11(10), 2481-2504$.

Tell, G., Quadrifoglio, F., Tiribelli, C., Kelley, M.R. (2009). The Many Functions of APE1/Ref-1: Not Only a DNA Repair Enzyme. Antioxid Redox Signal., 11 (3), 601-619.

Wang, Z., Rhee, D.B., Lu, J., Bohr, C.T., Zhou, F., Vallabhaneni, H., de Souza-Pinto, N.C., Liu Y. (2010). Characterization of Oxidative Guanine Damage and Repair in Mammalian Telomeres. PLoS Genet., 6 (5).

Watson, J.D. (1972). Origin of concatemeric T7 DNA. Nature: New biology, 239 (94), 197-201.

Webb, C.J., Wu, Y., Zakian, V.A. (2013). DNA Repair at Telomeres: Keeping the Ends Intact. Cold Spring Harb Perspect Biol., 5 (6).

Werner, C., Fürster, T., Widmann, T., Pöss, J., Roggia, C., Hanhoun, M., Scharhag, J., Buchner, N., Meyer, T., Kindermann, W., Haendeler, J., Böhm, M., Laufs, U. (2009). Physical exercise prevents cellular senescence in circulating leukocytes and in the vessel wall. Circulation, 120 (24), 2438-2447.

Werner, C.M., Hecksteden, A., Morsch, A., Zundler, J., Wegmann, M., Kratzsch, J., Thiery, J., Hohl, M., Bittenbring, J-T., Neumann, F., Böhm, M., Meyer, T., Laufs, U. (2019). Differential effects of endurance, interval, and resistance training on telomerase activity and telomere length in a randomized, controlled study. European Heart Journal, 40 (1), 34-46.

Xanthoudakis, S., Miao, G.G., Curran, T. (1994). The redox and DNA-repair activities of Ref-1 are encoded by nonoverlapping domains. Proceedings of the National Academy of Sciences of the United States of America, 91 (1), 23-27.

Xanthoudakis, S., Smeyne, R.J., Wallace, J.D., Curran, T. (1996). The redox/DNA repair protein, Ref-1, is essential for early embryonic development in mice. Proceedings of the National Academy of Sciences of the United States of America, 93 (17), 8919-8923.

Yang, J-L., Yu-Lin, T., Chuang, P-C., Bohr, V.A., Mattson, M.P. (2014). BDNF and Exercise Enhance Neuronal DNA Repair by Stimulating CREB-Mediated Production of Apurinic/Apyrimidinic Endonuclease 1. Neuromolecular Med., 16 (1), 161-174.

Zahler, A.M., Williamson, J.R., Cech, T.R., Prescott, D.M. (1991). Inhibition of telomerase by G-quartet DNA structures. Nature, 350 (6320), 718-720.

Zglinicki, T., Pilger, R., Sitte, N. (2000). Accumulation of single-strand breaks is the major cause of telomere shortening in human fibroblasts. Free Radical Biology and Medicine, 28 (1), 64-74.

Zuo, L., Hallman, A.H., Yousif, M.K., Chien, M.T. (2012). Oxidative stress, respiratory muscle dysfunction, and potential therapeutics in chronic obstructive pulmonary disease. Front. Biol., 7 (6), 506-513.

Cite this article aS: Betlej, G., Kwiatkowska, A., Bator, E. (2019). The Modulatory Effect of Physical Activity on APE1-Mediated Telomere Length and Stability; A Narrative Review. Central European Journal of Sport Sciences and Medicine, 4 (28), 97-106. DOI: 10.18276/cej.2019.4-09. 